This item was submitted to Loughborough's Institutional Repository (https://dspace.lboro.ac.uk/) by the author and is made available under the following Creative Commons Licence conditions.

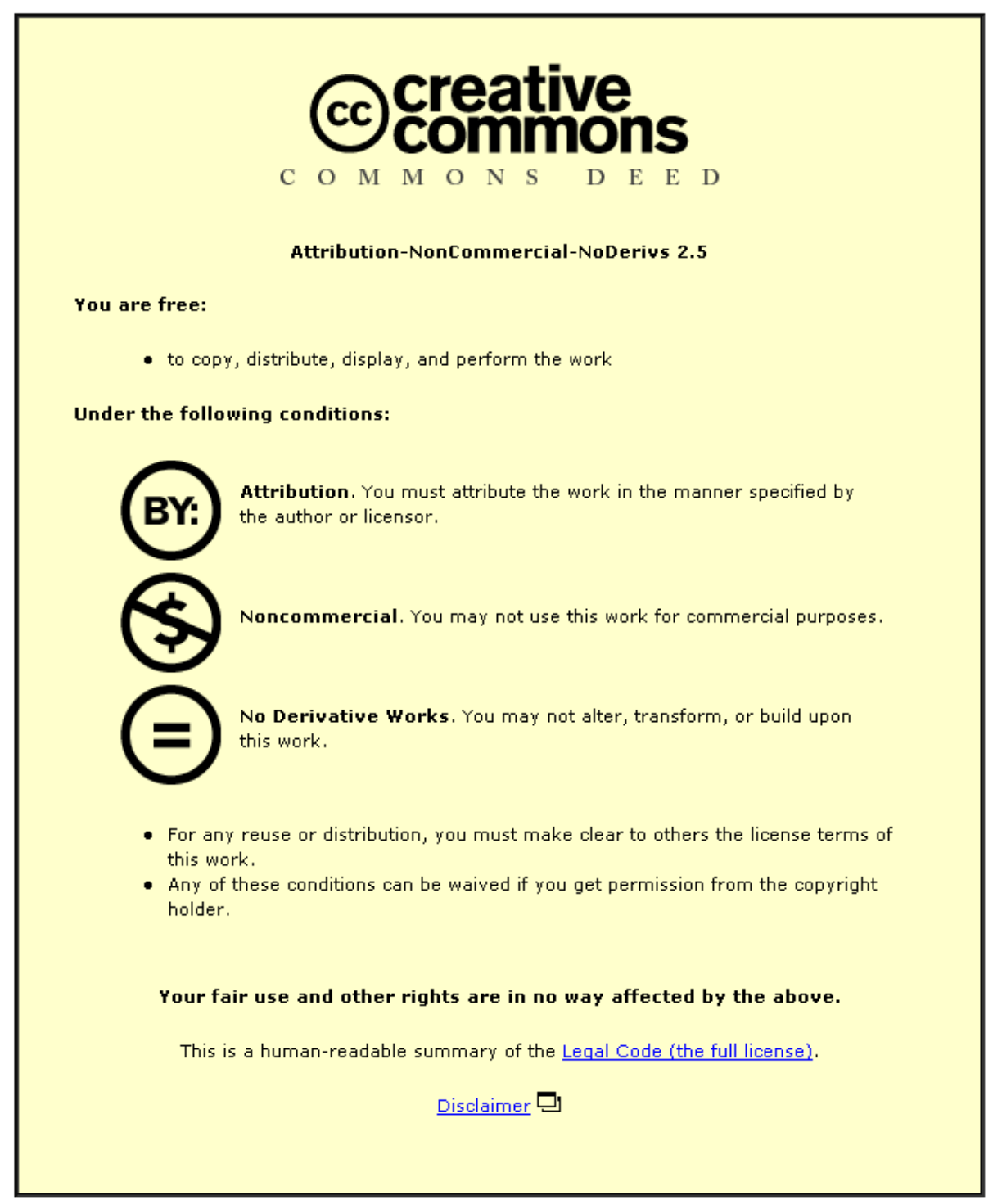

For the full text of this licence, please go to: http://creativecommons.org/licenses/by-nc-nd/2.5/ 


\section{Preparation and Thermal Characterisation of Poly(Lactic Acid) nanocomposites Prepared from Organoclays based on an Amphoteric Surfactant}

McLauchlin, A.R. and Thomas, N.L.

Department of Materials, Loughborough University, Loughborough, Leicestershire, LE11 3TU, UK

\section{Abstract}

New polymer-clay nano-composites composed of poly(lactic acid) and a novel organoclay based on cocamidopropylbetaine (CAB) and sodium montmorillonite (MMT) were prepared by solution casting and characterised by X-Ray Diffraction Analysis (XRDA), Transmission Electron Microscopy (TEM) and Thermogravimetric Analysis (TGA). A similar series of composites based on PLA and Cloisite 30B, a commercially available organoclay, were prepared for comparison. The thermal stability of the CAB-MMT organoclays decreased with increasing surfactant loading. Experimental organoclays with an organic content similar to that of the commercial organoclay were found to be of comparable thermal stability. XRDA analysis of the PLA-organoclay nano-composites showed that PLA intercalated the gallery space of both types of organoclay to similar extents and the increased spacing was confirmed by TEM. The thermal stabilities of the PLA-organoclay composites based on CAB-MMT were higher than those based on the commercial organoclay.

\section{Introduction}

Biopolymers are receiving increasing attention from the plastics industry as the price of crude oil continues to rise. One such polymer is poly(lactic acid) which is currently produced in commercial quantities by fermenting dextrose derived from maize[1,2]. PLA is a strong contender in the plastics market, having similar properties to PET, which make it suitable for the food packaging sector. To secure its foothold in the market, it is desirable to 
optimise its physical properties, including thermal stability: the development of PLA nanocomposites is one way of addressing these issues.

An important property of a candidate organoclay filler is its thermal stability. Ideally the filler should be stable to degradation at the processing temperature of the polymer. Poly(lactic acid) (PLA) for example is typically processed at temperatures between $170^{\circ} \mathrm{C}$ and $200^{\circ} \mathrm{C}$ [3-7]. The use of the organoclay Cloisite 30B both in melt-processing and in-situ intercalative polymerisation of PLA has been reported[3,4,8,9] to give exfoliated nanocomposites. The degradation onset of Cloisite $30 \mathrm{~B}$ is given as $220^{\circ} \mathrm{C}$ by the manufacturers. Alternative nanofillers with similar stabilities are therefore suitable candidate materials for study.

To date, the reported work has focused on using organoclays containing quaternary ammonium compounds based on hydrogenated tallowalkyls which are derived from animal fats. An alternative class of organoclay could be based on quaternary ammonium compounds derived from plant oils such as coconut oil. Such fillers would be suitable for use in packaging applications where animal products would not be desirable, such as vegan foods.

Another type of quaternary compound is the betaine group which contains both quaternary ammonium and carboxyl moieties. These are interesting molecules whose net charge is $\mathrm{pH}$-dependent so they acquire a negative charge at higher $\mathrm{pH}$ values and a positive charge in acid conditions. A readily obtainable surfactant is cocamidopropylbetaine (CAB) (Figure 1) which is a derivative of coconut oil that is much used in personal hygiene products.

This surfactant also affords the possibility of introducing a second functionality, namely the carboxyl group, into the nanocomposite matrix at the interface between the silicate surface and the polymer. This carboxyl group could interact with the polar regions of the PLA chain in the same way as proposed for the hydroxyls of C30B [10]. Carboxyl groups have been shown to be protonated in the highly acidic environment of the interlayer space[11]. 
It has also been shown that the carboxyl group in CAB-MMT organoclay can catalyse curing in epoxy resins[12,13].

A useful way of assessing the suitability of an organic modifier for use with a particular polymer is to estimate the solubility parameter by summing the group contributions of the molecule[14]. There are various ways of doing this and this has been successfully used to predict, for example, that Cloisite 30B should show greater compatibility with PLA than other organoclays such as Cloisite 25A and 15A which are based on different substituted tallowalkyls[10]. For the purposes of the present study, the solubility parameters of PLA, CAB and the modifier of $\mathrm{C} 30 \mathrm{~B}$ were calculated by the methods of Hoftyzer-van Krevelen, Fedors and Hoy and these are given in Table 1. From this it can be seen that organoclays based on CAB should show similar compatibility with PLA as Cloisite 30B. The preparation and characterisation of a series of novel organoclays based on cocamidopropylbetaine and montmorillonite has already been reported in the literature [15]

In the current study, organoclays prepared from $\mathrm{CAB}$ and montmorillonite have been used to make PLA nanocomposites by solution casting. These PLA nanocomposites were characterised and compared with similar composites prepared using PLA and a commercial organoclay.

\section{Experimental}

\section{Materials}

The organoclays (Cloisite-Na and Cloisite 30B) were obtained from Southern Clays, Texas, US and used as supplied.

Poly(L-lactic acid) (PLA) was obtained from Hycail B.V.

Other reagents were obtained from Fisher Scientific, Loughborough, UK.

\section{Preparation}

Preparation of CAB-Montmorillonite Organoclay

Sodium montmorillonite (Cloisite- $\mathrm{Na}, 1.00 \mathrm{~g}$ ) was suspended in deionised water $(50 \mathrm{ml})$ by stirring for 2 hours after which the surfactant was added, 
followed immediately by sufficient hydrochloric acid to maintain the $\mathrm{pH}$ below 3. Stirring was maintained for a further 24 hours after which time the clay was harvested by centrifuge. To remove excess surfactant, the clay pellet was resuspended in deionised water $(100 \mathrm{ml})$ and centrifuged again. This was repeated six times for each sample. A range of samples was prepared by varying the amount of surfactant relative to the weight of clay calculated on a charge basis, assuming one positive charge per molecule of betaine. The range was from 0.2 to 16 times the cation exchange capacity (CEC) of the clay which was given as 92 milliequivalents per $100 \mathrm{~g}$ by the manufacturer.

\section{Preparation of PLA-Organoclay composites}

The organoclay $(0.1 \mathrm{~g}-0.04 \mathrm{~g})$ was suspended in chloroform (dried over $\left.\mathrm{MgSO}_{4}, 10 \mathrm{ml}\right)$. Poly(lactic acid) (PLA, 0.5g) was stirred in dried chloroform $(10 \mathrm{ml})$ to give a $5 \%$ solution which was then added dropwise to the chloroform/clay suspension. Stirring was continued for another 24 hours after which the suspensions were poured into clean glass Petrie dishes and left covered in a fume hood until the chloroform had evaporated. Typically, this took 24 hours. The films were then dried in a vacuum oven $\left(40^{\circ} \mathrm{C}, 24\right.$ hours) to remove residual traces of chloroform.

\section{Characterisation}

Thermal Gravimetric Analysis was performed on a Hi-Res Modulated TGA 2950 Thermogravimetric Analyzer (TA Instruments). The analysis was run at $15^{\circ} \mathrm{C} / \mathrm{min}$ in an air atmosphere. The organic content of the organoclay was determined from the weight loss between $200^{\circ} \mathrm{C}$ and $500^{\circ} \mathrm{C}$.

For TEM analysis, specimens were embedded in epoxy resin and cut to 100um thickness with a Cambridge Instruments Ultramicrotome. Microscopy was done using a JEOL 100CX Transmission Electron Microscope. 
X-Ray diffraction data were collected on a Brucker D8 Diffractometer using graphite-filtered $\mathrm{Cu}-\mathrm{Ka}$ radiation $(\lambda=1.542 \mathrm{~nm})$. The diffractometer was controlled using Diffrac Plus XRD Commander and the raw data was manipulated using EVA software. The organoclay specimens were pressed into an aluminium holder where sufficient sample was available, otherwise they were spread on a silicon wafer and pressed to give a flat surface at the reference plane. The PLA/organoclay nanocomposites sheets were laid flat on an aluminium block, the height of which was always adjusted so that the sample surface was the reference plane of the instrument.

\section{Results and Discussion}

Thermogravimetric analysis is a useful tool for rapidly assessing the thermal stability of materials in air or other atmospheres such as nitrogen. The thermal decomposition of CAB in air is shown in Figure 1. If it assumed that the start of decomposition is indicated when the rate of weight change with temperature, $\mathrm{dWt} \% / \mathrm{dT}$, is equal to $0.025 \% /{ }^{\circ} \mathrm{C}$, then thermal decomposition of the molecule commenced at $225^{\circ} \mathrm{C}$ and the maximum in the derivative weight curve reached a maximum at $243^{\circ} \mathrm{C}$. Another smaller weight loss started at $262^{\circ} \mathrm{C}$, with a derivative weight maximum at $272^{\circ} \mathrm{C}$. A final small weight loss occurred between $550^{\circ} \mathrm{C}$ and $560^{\circ} \mathrm{C}$. It is suggested that the initial weight loss was due to decomposition of the alkyl portion of the molecule and that the second portion was due to decomposition of the betainic part[16]. The third decomposition may have been due to volatilisation of trace inorganic components such as chloride.

Figure 3 shows the thermograms of Cloisite 30B and a CAB-mmt organoclay of similar interlayer spacing and organic content as shown in Table 2. The traces showing the weight loss $(\mathrm{W} \%)$ of the two materials both show an initial weight loss corresponding to loss of bound water. The differential plot $(\mathrm{dW} / \mathrm{dT})$ showed that this loss occurred at a higher temperature with CABmmt than $\mathrm{C} 30 \mathrm{~B}$, indicating that the water was more strongly retained by the 
former material and it is suggested that this is due to the effect of the hydrophilic betaine group.

It has been shown in studies using TGA-MS that the organic component of alkylamine-modified clays begins to degrade around $180^{\circ} \mathrm{C}$ by Hoffman degradation of the quaternary ammonium group[17]. It was also stated that the onset temperature was independent of factors such as architecture (dimethyl cf trimethyl substitution on the quaternary group); exchanged ratio or preconditioning such as washing. However other studies have shown that bromide-containing impurities decreased the thermal stability of alkylammonium organoclays and removing these led to an increase of degradation onset temperature of more than $100^{\circ} \mathrm{C}[18]$. As it has been shown that weight loss around $155^{\circ} \mathrm{C}$ is due to water desorption[17] the onset degradation in this paper was defined as the temperature above $170^{\circ} \mathrm{C}$ where $\mathrm{dWt} \% / \mathrm{dT}=0.025 \% /{ }^{\circ} \mathrm{C}$. Using this criterion, the degradation onset temperatures of $\mathrm{C} 30 \mathrm{~B}$ and $\mathrm{CAB}-\mathrm{MMT}$ were very similar (Table 2).

The differential trace of C30B shows two peaks between 200 and $400^{\circ} \mathrm{C}$. It has been proposed that these peaks correspond to specific environments for the adsorbed surfactant [16] such that peaks at, $270-290$ and $370-385^{\circ} \mathrm{C}$ represent decomposition of intercalated surfactant molecules and the surfactant cations respectively. Using these criteria, it can be seen that the cationic group of $\mathrm{C} 30 \mathrm{~B}$ decomposes around $375^{\circ} \mathrm{C}$ as shown by the strong peak whereas in the case of CAB-MMT the peak is not evident at this temperature. However the peak for CAB-MMT shows a shoulder which may correspond to a lower decomposition temperature for the betaine group.

In order to determine the effect of surfactant loading on the thermal stability of the organoclay, a series of organoclays was prepared and characterised by TGA and XRDA. In accordance with the findings of other workers, it was found that the basal spacing of the organoclay increased in a stepwise fashion $[19,20]$ while the surfactant loading as indicated by the organic content increased in a steady asymptotic manner and this is reported elsewhere[15]. 
In Figure 4 it can be seen that the degradation onset temperature as defined above decreased with increasing organic content. A second-order polynomial curve was fitted to the data with an $r^{2}$ value of 0.94 . A sample of Cloisite 30B run under the same conditions and subjected to the same criteria showed an onset degradation temperature that lay within the experimental plot, indicating that the thermal stability of the commercial organoclay was comparable with that of an experimental clay of similar organic content. This relationship between organic content and degradation onset temperature accounts for the slightly lower thermal stability of CAB-MMT compared to C30B which has a slightly lower organic content.

PLA nanocomposites were then made from both types of organoclay by solution-casting from chloroform to produce intercalated nanocomposites. The preparation conditions were adapted from those used elsewhere[10]. The XRDA traces are shown in Figure 5 and Figure 6. In the Cloisite30B/PLA composites, the signal due to $\mathrm{C} 30 \mathrm{~B}\left(2 \theta=4.88^{\circ}, 1.81 \mathrm{~nm}\right)$ was evident in all three treatments, while a weak signal at $2 \theta=2.54^{\circ}$ indicated that some intercalation had occurred, expanding the interlayer spacing to $3.48 \mathrm{~nm}$. In the CABmmt/PLA composites, the signal due to the organoclay $\left(2 \theta=4.80^{\circ}\right.$, $1.84 \mathrm{~nm}$ ) disappeared while a strong signal at $2 \theta=2.16^{\circ}$ appeared indicating expansion to $4.09 \mathrm{~nm}$. The strength of this signal indicated that there was a significant amount of intercalated and ordered nanoclay in the composite. Second- and third-order signals were also seen due to the strength of this first-order signal. The experimental clay was therefore highly compatible with the PLA in this system and is probably due to the chemical nature of the cocamidopropylbetaine molecule which contains moieties potentially capable of interacting with the PLA chains through hydrogen bonding. Examination of the composites by TEM confirmed the ordered structure associated with intercalated composites (Figure 7).

The thermal stability of the composites was examined using TGA. The gravimetric thermograms of the $8 \%$ clay content nanocomposites for shown in Figure 8 and the degradation onset temperatures are given in Table 3 . It can be seen that in all cases, introducing a nanoclay increased the degradation 
onset temperature of $\mathrm{PLA}$ from $276^{\circ} \mathrm{C}$. The highest onset temperature occurred at $4 \%$ clay which is in agreement with the findings of other workers [21]. The increase in the degradation onset temperature can be attributed to effects such as a decrease in permeability due to the so-called 'tortuous path' effect of the filler which delays the permeation of oxygen and the escape of volatile degradation products and also char formation[22,23]. In addition, there may be thermodynamic effects arising from the presence of the filler, as it has been shown that the activation energy of thermal degradation of epoxyclay nanocomposites increased with organoclay loading to a maximum around 4-6phr, decreasing rapidly at higher loadings up to $14 \mathrm{phr}[13]$.

\section{Conclusions}

A novel organoclay was made by combining cocamidopropylbetaine with montmorillonite. This organoclay was found to have similar thermal stability to a commercial organoclay that has been reported to be compatible with poly(lactic acid). Using this organoclay, a series of novel nanocomposites were prepared using poly(lactic acid) as the matrix polymer by solutioncasting from chloroform. By using XRDA is it was shown that the CABmmt readily intercalated PLA to give ordered intercalated nanocomposites and this was confirmed by TEM. Thermogravimetric analysis indicated that the thermal stability of the PLA-CABmmt nanocomposites depended on the organoclay content, with the greatest thermal stability occurring at $4 \%$ organoclay content. The new organoclay is therefore a good candidate material for development of polymer-clay nanocomposites by other procedures such as melt-compounding.

\section{Acknowledgements}

The authors would like to thank Dr David Ross and Dr David Grandy for assistance with the XRDA and TGA characterisation of the materials. 


\section{References}

[1] JR Dorgan, HJ Lehermeier, LI Palade, J Cicero. Polylactides: Properties and Prospects of an Environmentally Benign Plastic from Renewable Resources, Macromolecular Symposia. 175 (2001) 55-66.

[2] G Scott, D Gilead, Degradable Polymers, Chapman \& Hall, 2-6 Boundary Row, London, SE1 8HN, UK, 1995.

[3] M- Paul, C Delcourt, M Alexandre, P Degee, F Monteverde, A Rulmont, et al. (Plasticized) Polylactide/(organo-)Clay Nanocomposites by in Situ Intercalative Polymerization, Macromol. Chem. Phys. 206 (2005) 484-498.

[4] Y Di, S lannace, E Di Maio, L Nicolais. Poly(lactic acid)/organoclay nanocomposites: Thermal, rheological properties and foam processing, J Polym Sci B. 43 (2005) 689-698.

[5] SS Ray, P Maiti, M Okamoto, K Yamada, K Ueda. New polylactide/layered silicate nancomposites. 1. Preparation, characterisation and properties, Macromol. 35 (2002) 3104-3110.

[6] M Pluta. Melt compounding of polylactide/organoclay: structure and properties of nanocomposites, Journal of Polymer Science. (2006) Part B, Polymer Physics. Vol. 44, no. 23.

[7] M Pluta, A Galeski, M Alexandre, M- Paul, P Dubois.

Polylactide/montmorillonite Nanocomposites and Microcomposites Prepared by Melt Blending: Structure and some Physical Properties, J Appl Polym Sci. 86 (2002) 1497-1506.

[8] M- Paul, C Delcourt, M Alexandre, P Degee, F Monteverde, P Dubois. Polylactide/montmorillonite Nanocomposites. Study of the Hydrolytic Degradation, Polym.Degrad.Stab. 87 (2005) 535-542.

[9] MT Thon-That, J Denault, W Leelapornpisit, Clays in poly(lactic acid) nanocomposites, (2007).

[10] V Krikorian, DJ Pochan. Poly (L-Lactic Acid)/layered Silicate Nanocomposite: Fabrication, Characterization, and Properties, Chemistry of Materials. 15 (2003) 4317-4324.

[11] P Di Leo. A nuclear magnetic resonance (NMR) and fourier-transform infrared (FTIR) study of glycine speciation on a Cd-rich Montmorillonite, Clay \& Clay Min. 48 (2000) 495-502.

[12] B Guo, X Ouyang, C Cai, D Jia. Exploitation of Introducing of Catalytic Centers into Layer Galleries of Layered Silicates and Related Epoxy Nanocomposites. I. Epoxy Nanocomposites Derived from Montmorillonite Modified with Catalytic Surfactant-Bearing Carboxyl Groups, J. Polym. Sci. B: Pol. Phys. 42 (2004) 1192-1198. 
[13] B Guo, D Jia, C Cai. Effects of Organo-Montmorillonite Dispersion on Thermal Stability of Epoxy Resin Nanocomposites, Eur. Polym. J. 40 (2004) 1743-1748.

[14] DWV Van Krevelen, Properties of Polymers, Elsevier, Amsterdam, 1990.

[15] AR McLauchlin, NL Thomas. Preparation and characterization of organoclays based on an amphoteric surfactant, J Coll. Inter. Sci. 321 (2008) 39-43.

[16] Y Xi, RL Frost, H He, T Kloprogge, T Bostrom. Modification of Wyoming Montmorillonite Surfaces Using a Cationic Surfactant, Langmuir. 21 (2005) 8675-8680.

[17] W Xie, Z Gao, W- Pan, D Hunter, A Singh, R Vaia. Thermal Degradation Chemistry of Alkyl Quaternary Ammonium Montmorillonite, Chem. Mater. 13 (2001) 2979-2990.

[18] RD Davisi, JW Gilman, TE Sutto, JH Callahan, PC Trulove, HC De Long. Improved Thermal Stability of Organically Modified Layered Silicates, Clays and Clay Minerals. Vol. 52, no. 2, pp. 171-179. 52 (2004) 171-179.

[19] Y Xi, Z Ding, RL Frost. Structure of Organo-clays - an X-ray Diffraction and Thermogravimetric Analysis Study, J. Colloid Interf. Sci. 277 (2004) 116120.

[20] G Lagaly. Interaction of Alkylamines with Different Types of Layered Compounds, Solid State Ionics. 22 (1986) 43-51.

[21] M- Paul, M Alexandre, P Degee, C Henrist, A Rulmont, P Dubois. New Nanocomposite Materials Based on Plasticized Poly(I-Lactide) and OrganoModified Montmorillonites: Thermal and Morphological Study, Polymer. 44 (2003) 443-450.

[22] JW Gilman. Flammability and Thermal Stability Studies of Polymer Layered-Silicate (Clay) Nanocomposites, Appl. Clay Sci. 15 (1999) 31-49.

[23] P Dubois, M Alexandre. Polymer-layered silicate nanocomposites: preparation, properties and uses of a new class of materials, Mater. Sci. Eng. 28 (2000) 1-63. 


\section{Figures}

Figure 1. Structure of cocamidopropylbetaine in dissociated and undissociated forms.

Figure 2. Thermogravimetric analysis of cocamidopropylbetaine (CAB)

Figure 3. Thermogravimetric Analysis (TGA) of Cloisite 30B and Cocamidopropylbetaine-montmorillonite $(\mathrm{CAB})$ organoclays

Figure 4. Degradation onset temperature of cocamidopropylbetainemontmorillonite organoclays as a function of organic content.

Figure 5. XRDA diffractograms of CAB-montmorillonite organoclay and PLA/CABmmt composites formed by solution casting.

Figure 6. XRDA diffractograms of C30B organoclay and PLA/C30B composites formed by solution casting.

Figure 7. TEM image of PLA/CABmmt intercalated composite prepared by solution casting.

Figure 8. Thermogravimetric analysis of PLA intercalated nanocomposites prepared by solution casting with Cloisite $30 \mathrm{~B}$ and $\mathrm{CABmmt}$ from chloroform.

\section{List of Tables}

Table 1. Solubility parameters of PLLA and organoclay modifiers as calculated by various methods.

Table 2. Organic content of commercial and experimental organoclays.

Table 3. Thermal Stability of PLA and PLA/organoclay nanocomposites as determined by TGA. 
Figure 1. Structure of cocamidopropylbetaine in dissociated and undissociated forms. $\mathrm{R}=9 \% \mathrm{C} 8 ; 6 \% \mathrm{C} 10 ; 49 \% \mathrm{C} 12 ; 20 \% \mathrm{C} 14 ; 8 \% \mathrm{C} 16 ; 8 \% \mathrm{C} 18$.<smiles>[R]C(=O)NCCC[N+](C)(CCCNC([R])=O)OC(=O)[O-]</smiles>

Figure 2. Thermogravimetric analysis of cocamidopropylbetaine (CAB)

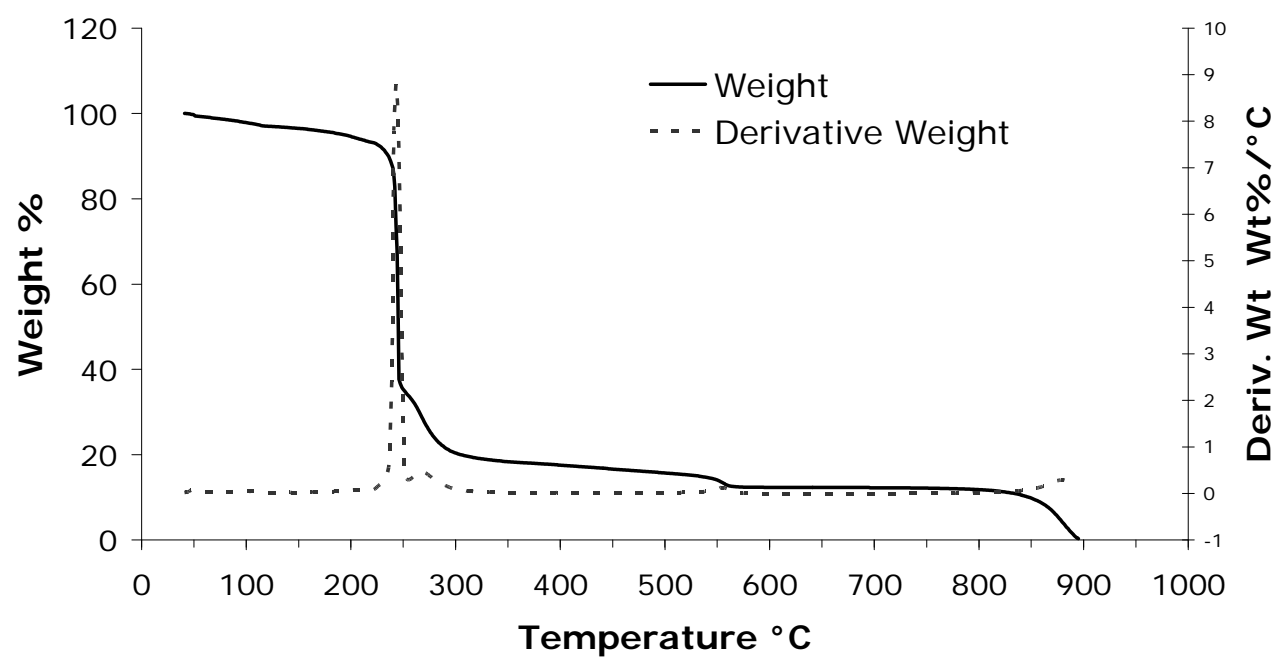

Figure 3. Thermogravimetric Analysis (TGA) of Cloisite 30B and Cocamidopropylbetaine-montmorillonite (CAB) organoclays

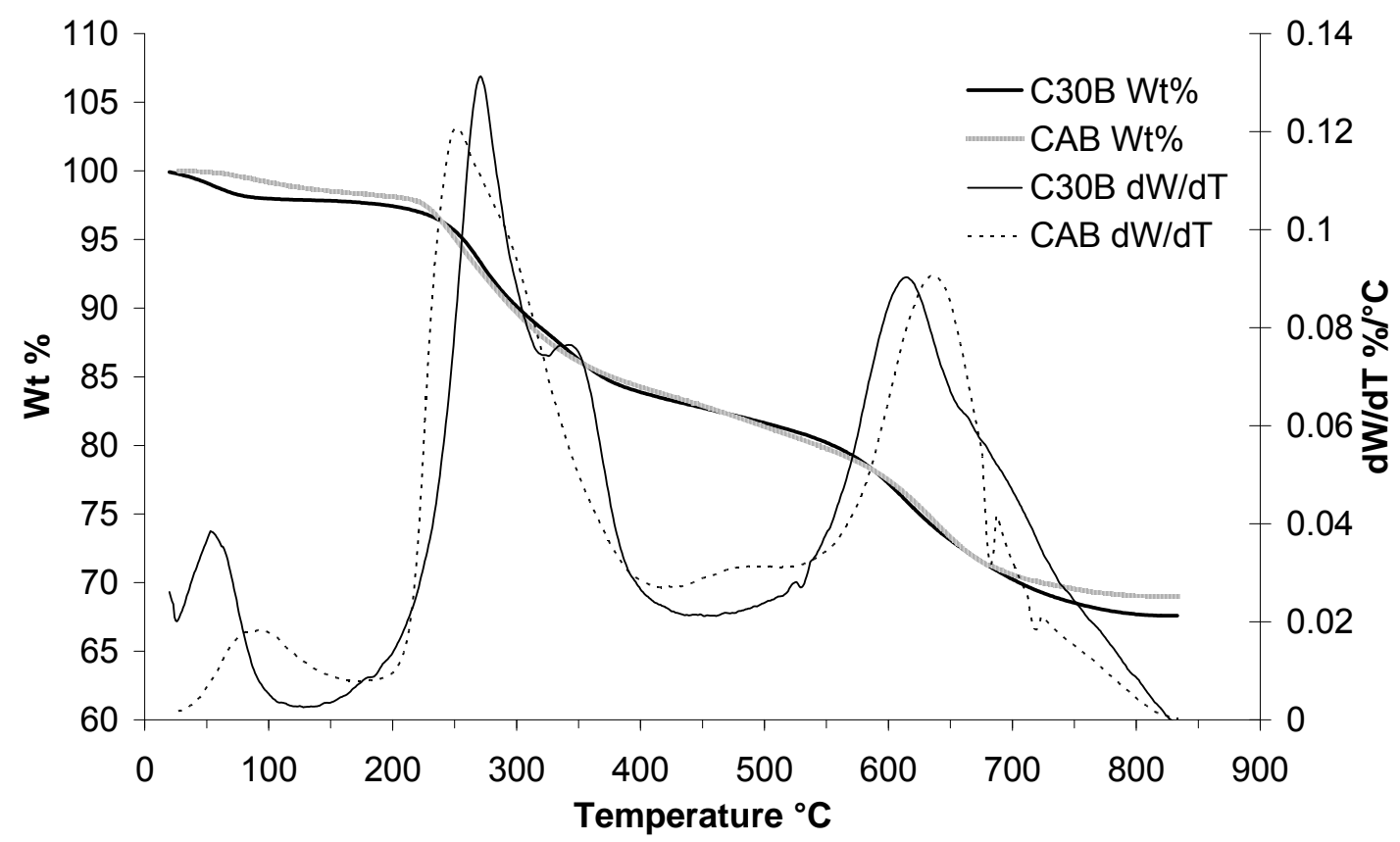


Figure 4. Degradation onset temperature of cocamidopropylbetaine-montmorillonite organoclays as a function of organic content.

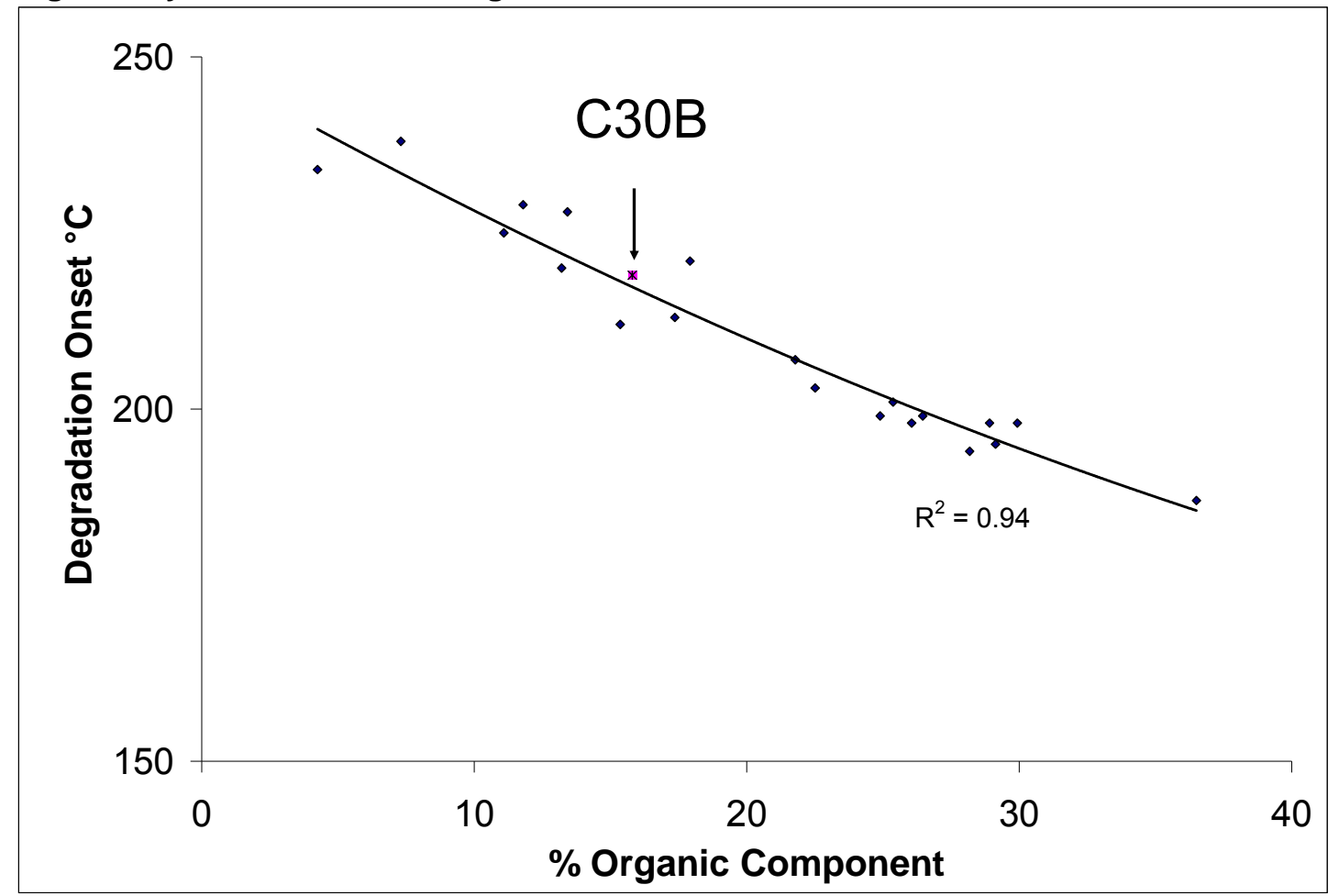


Figure 5. XRDA diffractograms of CAB-montmorillonite organoclay and PLA/CABmmt composites formed by solution casting.

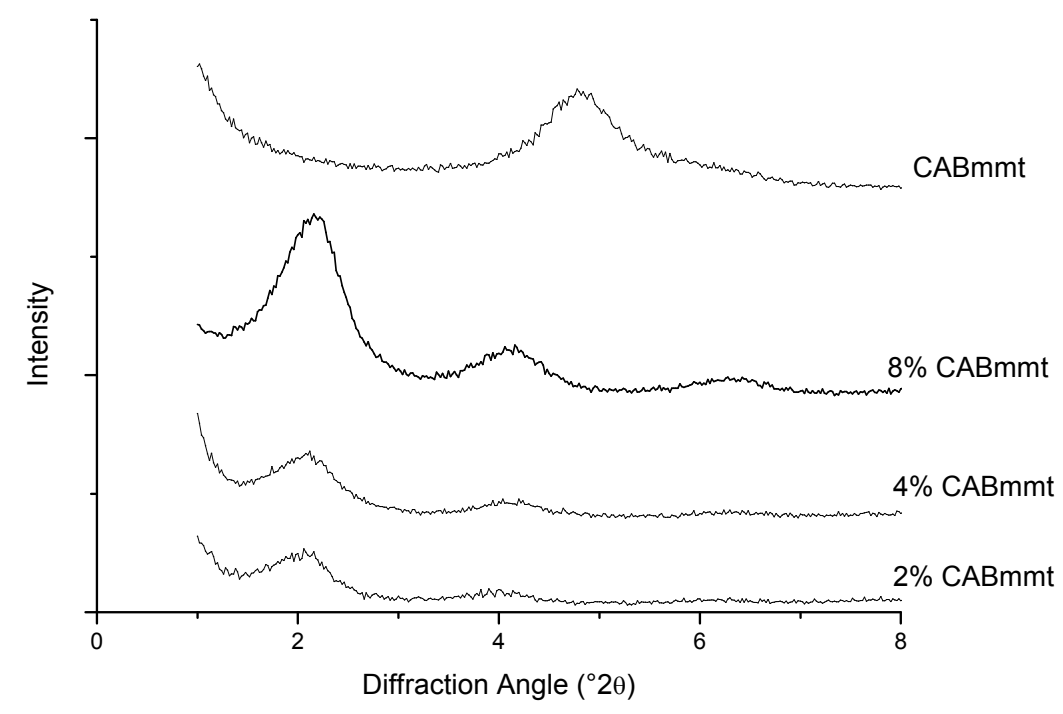

Figure 6. XRDA diffractograms of C30B organoclay and PLA/C30B composites formed by solution casting.

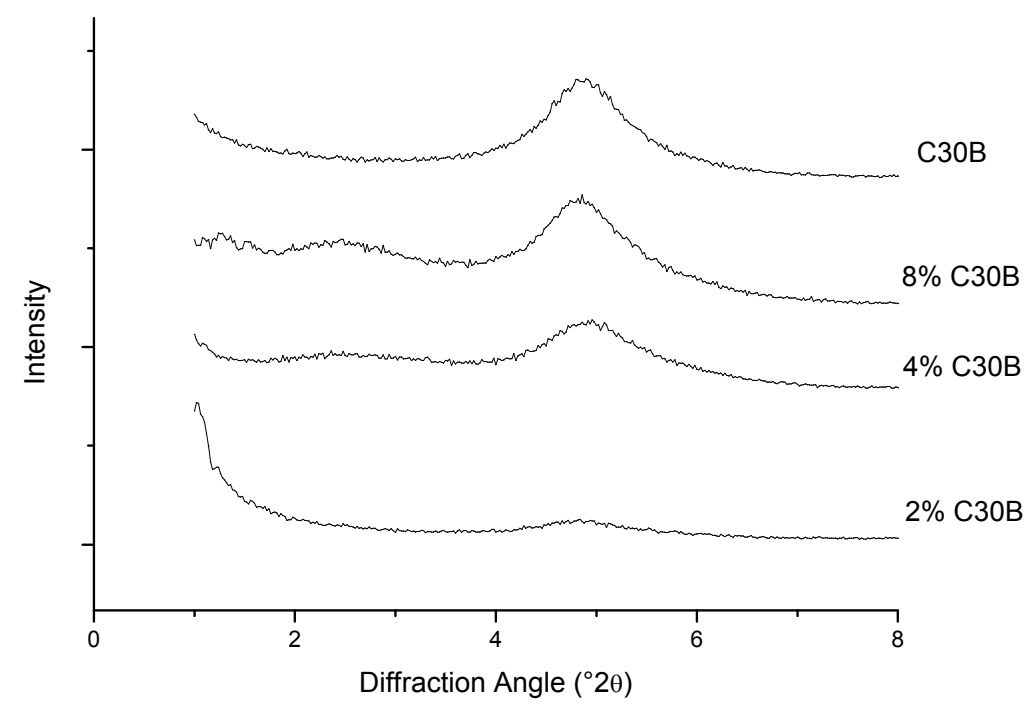


Figure 7. TEM image of PLA/CABmmt intercalated composite prepared by solution casting.

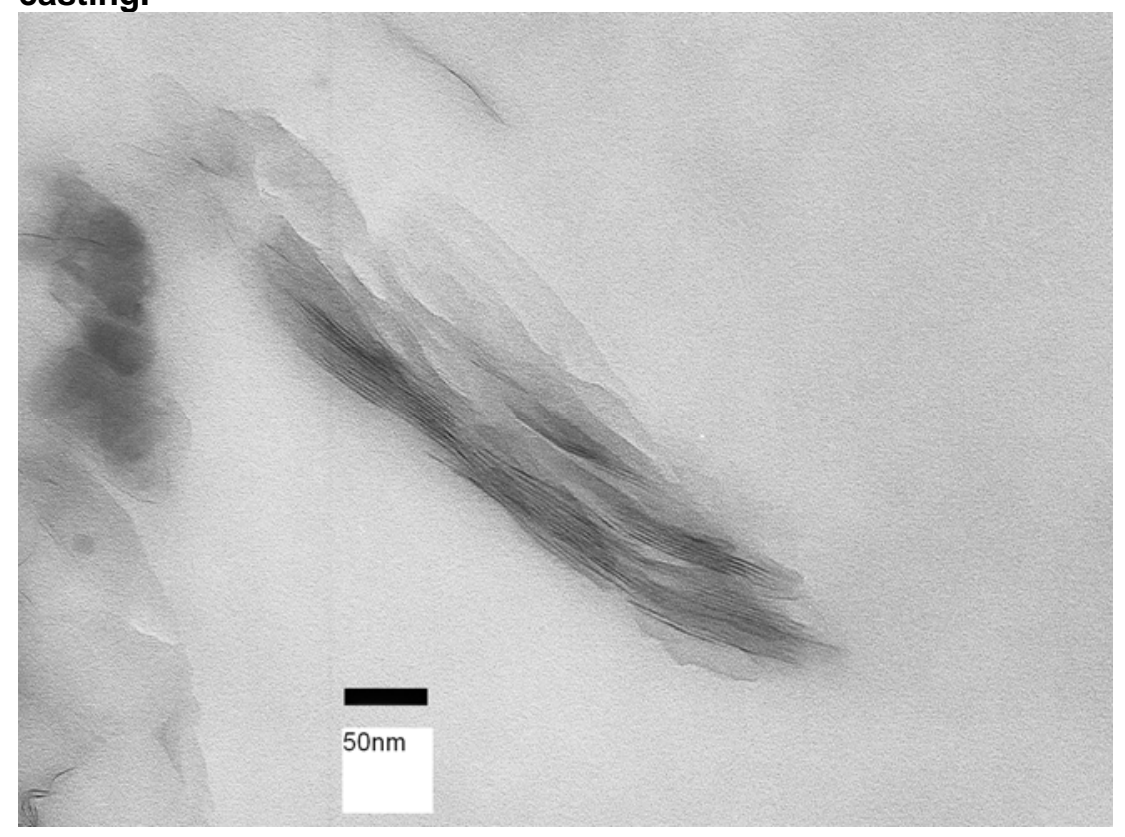

Figure 8. Thermogravimetric analysis of PLA intercalated nanocomposites prepared by solution casting with Cloisite30B and CABmmt from chloroform.

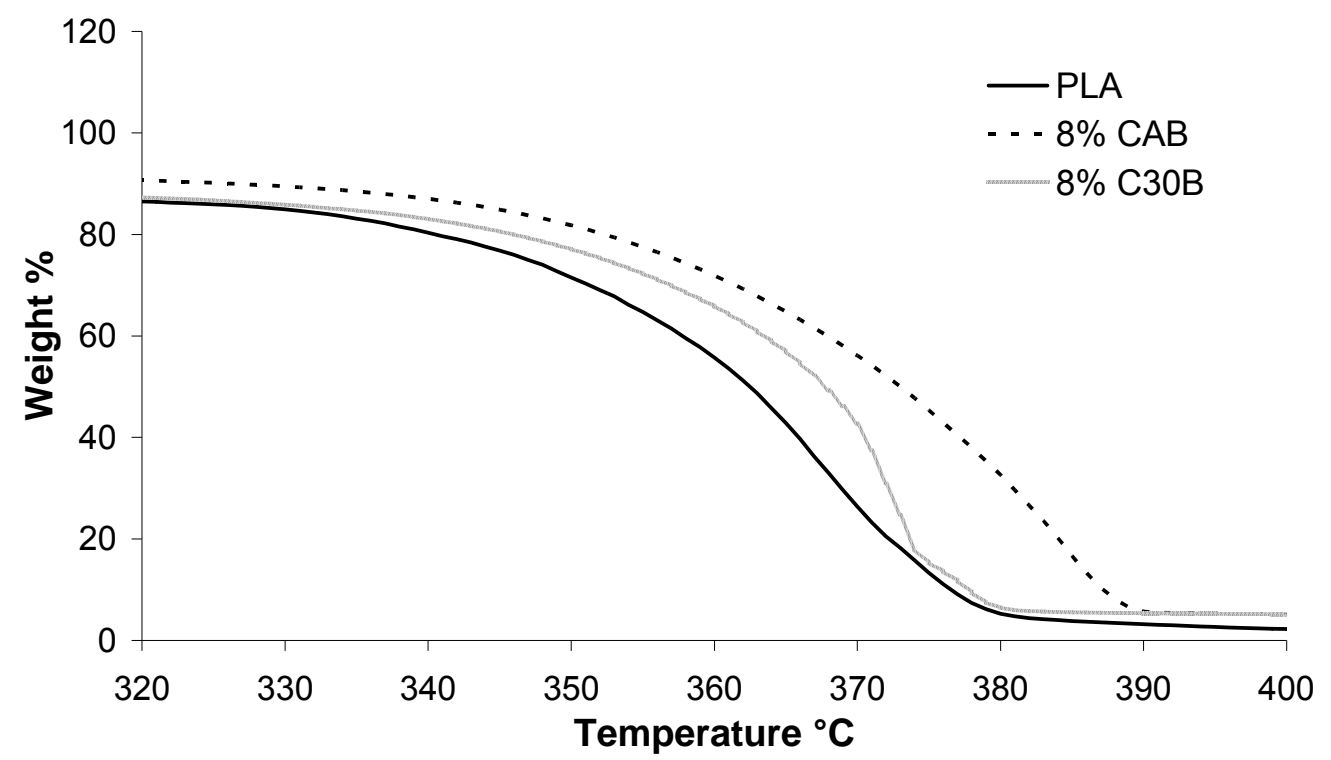


Table 1. Solubility parameters of PLLA and organoclay modifiers as calculated by various methods.

Substance

Solubility Parameter according to:

$\begin{array}{cccc}\text { Hoftyzer - Van } & \text { Hoy } & \text { Fedors } \\ \text { Krevelen } & & 21.28 & 22.75 \\ \text { PLLA } & 23.31 & 19.67 & 20.6 \\ \text { C30B } & 17.33 & 19.62 & 20.6 \\ \text { CAB } & 20.94 & & \end{array}$

Table 2. Organic Content and Degradation Onset Temperature of Commercial and Experimental Organoclays.

Organoclay \% Organic Component Deg Onset Temperature, ${ }^{\circ} \mathrm{C}$

C30B

CABmmt
15.8

16.8 (dWt/dT $>0.025 \% /{ }^{\circ} \mathrm{C}$ )

217

Table 3. Degradation Onset Temperature PLA and PLA/organoclay Nanocomposites.

\section{Organoclay content, \%}

0 (PLA)

2

4

8
Degradation Onset Temperature, ${ }^{\circ} \mathrm{C}$

C30B

276

296

310

285
CAB-mmt

276

288

305

289 